\title{
A Correlational Study on Analogical Reasoning, Mathematical Creativity, and Logical Operation of Primary School Prospective Teachers
}

\author{
Ifada Novikasari ${ }^{1}$, Fauzi $^{2}$ \\ \{ifa_da@iainpurwokerto.ac.id $\left.{ }^{1}\right\}$ \\ Mathematics Education, IAIN Purwokerto, Purwokerto, Indonesia ${ }^{1}$ \\ Early Childhood Education, IAIN Purwokerto, Purwokerto, Indonesia ${ }^{2}$
}

\begin{abstract}
The purpose of this study was to find the relationship between analogical reasoning, mathematical creativity, and logical operation developed by the prospective teachers. The research population was the fourth semester students of one state Islamic university in West Java and one state Islamic university in Central Java. A random sampling technique was used to obtain 47 primary school prospective teachers as the research samples from both universities. The results showed that (a) more than $50 \%$ of primary school prospective teachers had formal logical operation; (b) there was a significant relationship between analogical reasoning and mathematical creativity; (c) there was a significant relationship between mathematical creativity and logical operation; (d) there was no significant relationship between analogical reasoning and logical operation.
\end{abstract}

Keywords: Analogical reasoning, mathematical creativity, logical operation, prospective teacher

\section{Introduction}

Humans' daily activities cannot be separated from the mathematical activities, starting from the activities related to numbers to those requiring calculation. In fact, the mathematical concept which actually has a great benefit was known unreal and taught meaningless. According to Wijers and de Haan [1], mathematics is given to develop the logical thinking ways. Furthermore, Russefendi [2] asserts that by knowing the essence of the real mathematics, the teachers can select the most appropriate teaching and learning strategies in the classes. In fact, one key success of students in developing their logical thinking ways is related to a competent teacher. However, mathematics has an abstract research object and becomes one problem causing a teacher finds it difficult in teaching mathematics at school [3].

In response to the pedagogical and professional competence, a learning case was exemplified by $\mathrm{Wu}$ [4] stating that in Grade $6-8$ of primary education levels, the students should have been taught fraction with minimum abstraction and basic mathematical abstraction. In fact, those materials have not been strongly given to the primary education students. Furthermore, the researchers conducted preliminary research on (Islamic) Primary School teachers who have been teaching for 7 years at (Islamic) Primary Schools related to how the teachers taught the following fraction addition to the students who have just known about the fraction calculation operation. 
The (Islamic) Primary Teachers smoothly explained that:

$\frac{1}{3}+\frac{1}{2}=\frac{1}{3 \times 2}+\frac{1}{2 \times 3}=\frac{2}{6}+\frac{3}{6}=\frac{5}{6}$

It was found that the teachers found it difficult to concretely explain that routine problem. The problem faced by the teachers and higher education students above was not purely their mistakes. Thus, it is necessary to investigate the prospective teachers' education processes in the Teacher Training Institute (known as LPTK/Lembaga pendidikan Tenaga Kependidikan). The ability as explained in the case of preliminary research above was identified by Sriraman [5] showing that analogical reasoning is essentially possessed by the prospective teachers to form a conceptual knowledge in the (Islamic) Primary School students' thinking levels. According to Richland and Begolli [6], in-depth understanding will be obtained by the students if the teachers have taught the mathematical concept using analogy. Furthermore, according to Poincare in [7], what is obtained in the analogical reasoning process is one characteristic of creative attitudes, that is, an activity to obtain knowledge from a problem in analogical reasoning as a knowledge source to obtain the other knowledge.

The analysis on the preliminary research result shows that the students as prospective (Islamic) primary teachers should not only well master the analogical reasoning but also the mathematical creativity ability related to the mathematical concept mastery and adjustment to the students' thinking level in various ways. Based on the learning readiness age according to Piaget, the students at the (Islamic) primary school are in the concrete thinking level, while the higher education students as the (Islamic) primary school prospective teachers according to Ojose [8] are at the formal operation level. The higher education students as the prospective teachers at the formal operation level are expected to have the analogical reasoning and mathematical creativity ability to teach at the level of (Islamic) primary school levels or concrete operation stages. Thus, this research will try to describe the logical operation level of the higher education students as the (Islamic) primary school teachers and the relationship between analogical reasoning, mathematical creativity, and logical operation developed by the prospective teachers.

\subsection{Analogical Reasoning}

Analogy is inductive mechanism based on the structural comparison from the mental representation. According to Gentner \& Smith [9], analogy is the core of higher-order cognition. Humans' analogical reasoning highly depends on the work of memory and important functions supporting the brain parts [10].

According to Gentner and Smith [9], analogical reasoning is the ability to feel and use the similarity relationship between two situations or events and considered as an important aspect in humans' logic. According to Polya in [11], an evidence is considered incomplete if only found and written. The most important step is analyzing and learning from the evidence to solve the future problems. There are many different approaches in obtaining the analogical aspects, including setting or mapping between the analog and abstraction part in a general conclusion.

According to Sriraman [5], mathematics can be obtained using various analogies. If the students find some concepts which are too abstract to solve, one of the strategies used to help 
the students build their conceptual knowledge is using their analogy. For example, the best way to teach the abstract relation is by making an alignment among the similar examples [12].

The analogical reasoning intended in this research is the students' ability to use the relational relationship to analyze the problem. This ability is greatly important to teach mathematics. The (Islamic) primary school teachers have the ability to use their analogy from the abstract mathematical concept to be related with the existing context in the students' surroundings.

\subsection{Mathematical Creativity}

Creativity is simply described by Poincare as sharpness or choice. Referring to Poincare, the first stage mentions that creativity is obtained from work to obtain knowledge from, a problem, called as preparatory Stage. The second stage is incubatory, that is, a problem is set aside for a certain period and logic is used for the other problem. The third stage is illuminatory, that is, problem solving may surprisingly arise when an individual does the other unrelated activity. However, the creativity process has not yet ended in this stage. The fourth stage is expressing the solution in language or writing [7].

According to Guilford in [13] associating fluency, flexibility, and originality is an important aspect in creativity known as structure from intellect model. Fluency shows some outputs, flexibility shows some type changes (meaning, interpretation, strategy) in term of new objective meaning. Originality thinking means extraordinary, different, or more brilliant response results. Elaboration in thinking means someone's ability to result in an obvious step in making the working plan. Guilford thinks that creative thinking obviously involves classification as divergent results. According to Russefendi [2], the creativity character can be trained, habituated, and implanted in children since at their early age to explore, acquire, discover, and solve problems.

The mathematical creativity ability discussed in this research, especially in fluency, flexibility, and originality indicator is the base to assess the mathematical creativity due to the diversity and novelty of ideas created by the higher education students.

\subsection{Logical operation}

Logic generally means what is known and thought by someone. According to Jung et al. [14] all psychological processes in humans interact each other, as an example is related to what is being thought (logically) by someone on how someone feels (emotions). According to the intellectual model proposed by Guilford [15], operation is the possible intellectual action type when thinking, such as observation, memory, convergent product, divergent product, and evaluation. Thus, logical operation is someone's intellectual action interacting with all arising processes inside the individual himself.

When seeing from the age of the Islamic Primary School Teacher Education (known as PGMI/Pendidikan Guru Madrasah Ibtidaiyyah) students, their thinking stage should be at the formal operation level. Utilizing the logical feature developed in the theory of Piaget, this research was conducted to identify the students' thinking stages from logical operation, consisting of grouping, numbering, logical multiplication, compensation, proportion, opportunity, and correlation. Those identifications are based on the concrete operation that is, understanding the logical operation assisted with concrete things, while formal operation is a stage which has abstractly understood mathematics through concrete thing manipulations, by developing models, diagrams, etc. 


\section{Method}

This research used a quantitative correlational study. The research population was the fourth year's students of (Islamic) Primary School Teacher Education Study Program in one Islamic State University in West Java and one Islamic State University in Central Java. A random sampling technique was used to collect 47 students of prospective teachers. The instruments used are written tests to figure out their analogical reasoning, mathematical creativity, and logical operation ability in accordance with each indicator. The analogical reasoning and mathematical creativity ability tests were developed by the researchers. Meanwhile, the logical operation test was adopted from Test of Logical Operation (TLO) for mathematics developed by Leongson and Limjap [16]. The students' answers were analyzed using a guideline known as Holistic Scoring Rubrics from Cai, Lane and Jakabesin [17].

\section{Results and Discussion}

The presented research results include the description of (Islamic) Primary School prospective teachers' logical operation and the relationship of prospective teachers' analogical reasoning, mathematical creativity, and logical operation ability.

\subsection{Description of (Islamic) Primary School Prospective Teachers' Logical Operation Level}

The following is the division of logical operation levels proposed by Piaget [16] based on the obtained test scores covering the initial concrete stage with $0-35$; end concrete stage with 36 - 70; initial formal stage with $71-105$; and end formal stage with $105-140$. The obtained results presented in Table 1 .

Table 1. Percentages of (Islamic) Primary School prospective teachers' Logical Operation Level

\begin{tabular}{cc}
\hline Logical Operation Level & Percentage \\
\hline Initial Concrete & $2.13 \%$ \\
End Concrete & $17.02 \%$ \\
Initial Formal & $25.53 \%$ \\
End Formal & $55.32 \%$ \\
\hline
\end{tabular}

Table 2 shows that more than $50 \%$ of (Islamic) Primary School prospective teachers from both universities under study had been in the mathematical logical operation level of end formal. However, many (Islamic) Primary School prospective teachers (19.15\%) were at the concrete level. This finding was in line with that found by Bakir and Bİçer [18] using different tests by measuring the logical thinking ability of prospective science teachers and finding that $38.17 \%$ of prospective science teachers was at the concrete operation stage, $61.41 \%$ of prospective science teachers was at the transition stage, and $0.42 \%$ of prospective science teachers was at the formal stage. Using the same test, the research conducted by Leongson \& Limjap [16] on the prospective science teachers showed that the initial concrete level was at $10.17 \%$, end concrete at $50.85 \%$, initial formal at $28.81 \%$, and end formal at $10.17 \%$. These showed that there was a similarity of some prospective teachers' logical operation at the concrete level which should be at the formal level. There was a high percentage difference at the formal level in this 
research which probably caused by the (Islamic) Primary School prospective teachers in this research obtained the mathematical courses while the other research's samples were the prospective science teachers.

\subsection{The relationship of analogical reasoning, mathematical creativity, and logical operation ability of students of prospective mathematical teachers}

To know the relationship between variables in this research, the hypothesis testing to conduct was as follows.

$\mathrm{H}_{\mathrm{o}}$ : There is no relationship (correlation) between two variables

$\mathrm{H}_{\mathrm{i}} \quad$ : There is a relationship (correlation) between two variables

The decision was made based on the following principles [19]:

If probability is $\geq 0.05$, Ho is accepted

If probability is $<0.05 \mathrm{Ho}$ is rejected

The research results were obtained based on the SPSS program as follows:

Table 2. Relationship of Analogical reasoning, Mathematical creativity, and Logical operation

\begin{tabular}{lccc}
\hline \multicolumn{1}{c}{ Relationship } & Correlation & Probability & Conclusion \\
\hline Analogical reasoning - Creativity & 0.417 & 0.005 & Significant \\
Analogical reasoning - Logical operation & 0.266 & 0.071 & Not Significant \\
Creativity - Logical operation & 0.441 & 0.02 & Significant \\
\hline
\end{tabular}

Table 2 above shows that analogical reasoning-creativity and creativity-logical operation had positive and significant relationship. It means that the higher the first variable, the higher the second variable. This relationship was at the medium level. Higher analogical reasoning was related to the ability to feel and use the similarity relationship between two situations or events. This was also related to the creativity that is, using various strategies in solving the mathematical problems [20].

Positive and significant relationship between creativity and logical operation was caused by the creativity ability in mathematics used when determining various strategies. According to Leongson \& Limjap [16], logical operation can be identified from the ability of prospective teachers in solving problems. Thus, there was a relationship between the ability of mathematical creativity and logical operation, that is, the ability in solving the mathematical problems.

In this research, there was a positive relationship between analogical reasoning and logical operation. However, the relationship of both variables was not significant because logical operation contained reasoning in solving problems, yet in logical operation, the students analyzed and correlated different situations.

\section{Conclusion}

When related to the knowledge developed in someone, Piaget classified age at above 11 years old or the (Islamic) Primary School prospective teachers at the formal operation stage. The results of this research showed that more that 50\% of (Islamic) Primary School prospective teachers were at the formal logical operation level. However, there was no significant 
relationship between the ability of logical operation and analogical reasoning. Analogical reasoning itself is the ability to feel and use the similarity relationship between two situations or events as the important aspects in humans' logic. According to Poincare, one of those characteristics was creative character, that is, an activity to obtain knowledge from a problem. This supported a significant relationship between analogical reasoning and mathematical creativity. Besides, there was a significant relationship between mathematical creativity and logical operation. In the mathematical logical operation, the ability to solve problems developed as various strategies or mathematical creativity did.

\section{References}

[1] M. Wijers and D. de Haan, "Mathematics in Teams - Developing Thinking Skills in Mathematics Education," in National Reflections on the Netherlands Didactics of Mathematics, ICME-13 Mo., Van den Heuvel-Panhuizen M., Ed. Springer, 2020.

[2] E. Russefendi, "Pengantar kepada membantu guru mengembangkan kompetensinya dalam pengajaran matematik untuk meningkatkan CBSA," Tarsito, 2006.

[3] G. A. Goldin et al., Attitudes, Beliefs, Motivation and Identity in Mathematics Education: An Overview of the Field and Future Directions. 2016.

[4] $\mathrm{H}$. Wu, "What is so difficult about the preparation of mathematics teachers," CBMS Natl. Summit Math. Educ. Teach., pp. 1-44, 2001.

[5] B. Sriraman, "Mathematical and analogical reasoning of young learners," Zentralblatt für Didakt. der Math., 2005.

[6] L. E. Richland and K. N. Begolli, "Analogy and Higher Order Thinking: Learning Mathematics as an Example,” Policy Insights from Behav. Brain Sci., vol. 3, no. 2, pp. 160-168, 2016.

[7] B. Sriraman, "The characteristics of mathematical creativity," ZDM - International Journal on Mathematics Education. 2009.

[8] B. Ojose, "Applying Piaget's Theory of Cognitive Development to Mathematics Instruction," Math. Educ., vol. 18, no. 1, pp. 26-30, 2008.

[9] D. Gentner and L. Smith, Analogical Reasoning, 2nd ed., vol. 1. Elsevier Inc., 2012.

[10] K. J. Holyoak, “Analogy and Relational Reasoning,” Oxford Handb. Think. Reason., pp. 234-259, 2012.

[11] M. Kerber, "Some aspects of analogy in mathematical reasoning," Lect. Notes Comput. Sci. (including Subser. Lect. Notes Artif. Intell. Lect. Notes Bioinformatics), vol. 397 LNAI, pp. 231242, 1989.

[12] C. Hoyos and D. Gentner, "Generating explanations via analogical comparison,” Psychon. Bull. Rev., vol. 24, pp. 1364-1374, 2017.

[13] X. Yuan and B. Sriraman, "An Exploratory Study of Relationships between Students' Creativity and Mathematical Problem-Posing Abilities," in The Elements of Creativity and Giftedness in Mathematics, 2011.

[14] N. Jung, C. Wranke, K. Hamburger, and M. Knauff, "How emotions affect logical reasoning: evidence from experiments with mood-manipulated participants, spider phobics, and people with exam anxiety," Front. Psychol., vol. 5, p. 570, 2014.

[15] R. J. Sternberg and E. L. Grigorenko, "Guilford's structure of intellect model and model of creativity: Contributions and limitations," Creat. Res. J., vol. 13, no. 3-4, pp. 309-316, 2001.

[16] J. A. Leongson and A. A. Limjap, "Assessing the Mathematics Achievement of College Freshmen using Piaget's Logical Operations.," in Hawaii International Conference on Education in Waikiki, 2003, pp. 1-25.

[17] J. Cai, M. S. Jakabcsin, and S. Lane, “Assessing Students' Mathematical Communication,” Sch. Sci. Math., vol. 96, no. 5, pp. 238-246, 1996. 
[18] S. Bakir and E. Ö. Bİçer, "Logical Thinking and Cognitive Development Levels of," J. Educ. Sci. Res., vol. 5, no. 1, pp. 149-163, 2015.

[19] S. Santoso, Panduan Lengkap SPSS Versi 20. 2012.

[20] S. Bishara, "Creativity in unique problem-solving in mathematics and its influence on motivation for learning," Cogent Educ., vol. 3, no. 1, 2016. 